\title{
Subcellular Localization of Wild-Type and Parkinson's Disease-Associated Mutant $\alpha$-Synuclein in Human and Transgenic Mouse Brain
}

\author{
Philipp J. Kahle, ${ }^{1}$ Manuela Neumann, ${ }^{2}$ Laurence Ozmen, ${ }^{3}$ Veronika Müller, ${ }^{1}$ Helmut Jacobsen, ${ }^{3}$ \\ Alice Schindzielorz, ${ }^{1}$ Masayasu Okochi, ${ }^{1}$ Uwe Leimer, ${ }^{1}$ Herman van der Putten, ${ }^{4}$ Alphonse Probst, ${ }^{5}$ \\ Elisabeth Kremmer, ${ }^{6}$ Hans A. Kretzschmar, ${ }^{2}$ and Christian Haass ${ }^{1}$
}

${ }^{1}$ Adolf Butenandt Institute, Department of Biochemistry, Ludwig Maximilians University, 80336 Munich, Germany, 2Institute of Neuropathology, University of Göttingen, 37075 Göttingen, Germany, ${ }^{3}$ Pharma Research, Gene Technology, F. Hoffmann-La Roche Ltd., 4070 Basel, Switzerland, "Nervous System, Novartis Pharma Ltd., 4002 Basel, Switzerland, 5/nstitute of Pathology, University of Basel, 4003 Basel, Switzerland, and ${ }^{6}$ Gesellschaft für Strahlenschutzforschung Institute of Molecular Immunology, 81377 Munich, Germany

\begin{abstract}
Mutations in the $\alpha$-synuclein ( $\alpha \mathrm{SYN}$ ) gene are associated with rare cases of familial Parkinson's disease, and $\alpha \mathrm{SYN}$ is a major component of Lewy bodies and Lewy neurites. Here we have investigated the localization of wild-type and mutant $[\mathrm{A} 30 \mathrm{P}] \alpha \mathrm{SYN}$ as well as $\beta$ SYN at the cellular and subcellular level. Our direct comparative study demonstrates extensive synaptic colocalization of $\alpha \mathrm{SYN}$ and $\beta S Y N$ in human and mouse brain. In a sucrose gradient equilibrium centrifugation assay, a portion of $\beta S Y N$ floated into lower density fractions, which also contained the synaptic vesicle marker synaptophysin. Likewise, wild-type and $[\mathrm{A} 30 \mathrm{P}] \alpha \mathrm{SYN}$ were found in floating fractions. Subcellular fractionation of mouse brain revealed that both $\alpha$ SYN and $\beta S Y N$ were present in synaptosomes. In contrast to synaptophysin, $\beta S Y N$ and $\alpha$ SYN were recovered from the soluble fraction upon
\end{abstract}

Iysis of the synaptosomes. Synaptic colocalization of $\alpha \mathrm{SYN}$ and $\beta S Y N$ was directly visualized by confocal microscopy of doublestained human brain sections. The Parkinson's diseaseassociated human mutant [A30P] $\alpha$ SYN was found to colocalize with $\beta S Y N$ and synaptophysin in synapses of transgenic mouse brain. However, in addition to their normal presynaptic localization, transgenic wild-type and [A30P] $\alpha$ SYN abnormally accumulated in neuronal cell bodies and neurites throughout the brain. Thus, mutant $[\mathrm{A} 30 \mathrm{P}] \alpha \mathrm{SYN}$ does not fail to be transported to synapses, but its transgenic overexpression apparently leads to abnormal cellular accumulations.

Key words: synuclein; synaptophysin; brain; synapse; Parkinson's disease; Lewy body
Synucleins (SYNs) are $\sim 14$ kDa phosphoproteins predominantly expressed in brain. Members of the synuclein family include $\alpha \mathrm{SYN}$, $\beta S Y N, \gamma S Y N$ (Lavedan, 1998), and synoretin (Surguchov et al., 1999). The central domain of $\alpha \mathrm{SYN}$ had been originally identified as the non-amyloid $\beta$-protein component (NAC) of Alzheimer's disease plaques (Uéda et al., 1993). Full-length $\alpha \mathrm{SYN}$ has been subsequently found in Lewy bodies (LBs), pale bodies, and Lewy neurites of patients with Parkinson's disease (PD) and dementia with LBs, as well as in cytoplasmic inclusions characteristic for multiple system atrophy (Spillantini et al., 1997; Arima et al., 1998; Baba et al., 1998; Spillantini et al., 1998; Takeda et al., 1998a; Tu et al., 1998; Wakabayashi et al., 1998; Culvenor et al., 1999). LBs were $\alpha \mathrm{SYN}$-positive in LB variant of Alzheimer's disease, familial Alzheimer's disease, and Down's syndrome (Lippa et al., 1998, 1999; Takeda et al., 1998b), as well as in neurodegeneration with brain iron accumulation type 1 (formerly known as HallervordenSpatz disease) (Arawaka et al., 1998; Wakabayashi et al., 1999).

Two missense mutations in the $\alpha \mathrm{SYN}$ gene have been linked to familial PD (Polymeropoulos et al., 1997; Krüger et al., 1998). Both mutations accelerated the intrinsic property of $\alpha \mathrm{SYN}$ to selfaggregate into fibrils that were morphologically similar to those

Received April 6, 2000; accepted May 24, 2000.

This work was supported by Deutsche Forschungsgemeinschaft Grant HA 1737/4-1 to C.H. We gratefully acknowledge the donation of purified human brain $\alpha \mathrm{SYN}$ and $\beta S Y N$ by T. Iwatsubo, of purified human recombinant $\alpha$ SYN, $\beta S Y N$, and $\gamma \mathrm{SYN}$ by P. H. Jensen, and of Mab SY38 anti-synaptophysin by W. W. Franke and R. E. Leube. K. Mursch kindly provided brain tissue from lobotomized epilepsy patients. We thank S. Odoy and D. Bode for technical assistance and H. Schubert for animal care.

Correspondence should be addressed to Christian Haass or Philipp Kahle, Adolf Butenandt Institute, Department of Biochemistry, Ludwig Maximilians University, Schillerstrasse 44, 80336 Munich, Germany. E-mail: chaass@pbm.med. uni-muenchen.de or pkahle@pbm.med.uni-muenchen.de.

Copyright (C) 2000 Society for Neuroscience $0270-6474 / 00 / 206365-09 \$ 15.00 / 0$ isolated from LBs (Conway et al., 1998; Giasson et al., 1999; Narhi et al., 1999). Therefore, similar to most of the mutations associated with other familial forms of neurodegenerative disorders, $\alpha \mathrm{SYN}$ mutations lead to the abnormal generation of an amyloidogenic variant, which is deposited in the disease-specific lesion (Hardy and Gwinn-Hardy, 1998; Lansbury, 1999; Selkoe, 1999).

The physiological function of synucleins is unknown. Targeted disruption of the $\alpha \mathrm{SYN}$ gene in mice caused a subtle perturbation in dopaminergic neurotransmission (Abeliovich et al., 2000). The identification of $\alpha \mathrm{SYN}$ binding proteins has pointed to potential roles in signal transduction, perhaps in the context of axonal transport (Jenco et al., 1998; Engelender et al., 1999; Jensen et al., 1999; Ostrerova et al., 1999). Another link to signal transduction events may be indicated by the fact that both $\alpha$ SYN and $\beta S Y N$ are phosphorylated (Nakajo et al., 1993; Okochi et al., 2000).

Previous immunohistochemical studies suggested an enrichment of $\alpha \mathrm{SYN}$ and $\beta \mathrm{SYN}$ in presynaptic terminals, and subcellular fractionation studies revealed a potential synaptosomal localization of $\alpha \mathrm{SYN}$ and $\beta \mathrm{SYN}$ (Maroteaux and Scheller, 1991; ShibayamaImazu et al., 1993; Jakes et al., 1994; George et al., 1995; Iwai et al., 1995; Irizarry et al., 1996). Here we have directly compared the cellular expression of wild-type and the PD-associated mutant $[\mathrm{A} 30 \mathrm{P}] \alpha \mathrm{SYN}$ to that of $\beta \mathrm{SYN}$. The integral membrane protein synaptophysin was used as a marker for synaptic vesicles. Our direct comparative study demonstrates extensive synaptic colocalization of $\alpha \mathrm{SYN}$ and $\beta \mathrm{SYN}$ in human and mouse brain. In brains of transgenic mice expressing human mutant [A30P] $\alpha \mathrm{SYN}$, a synaptic colocalization with $\beta \mathrm{SYN}$ was found, suggesting that the mutation does not interfere with anterograde transport of $\alpha \mathrm{SYN}$ to synapses. However, in addition to the presynaptic localization, both transgenic wild-type and mutant [A30P] $\alpha$ SYN abnormally accumulated in neuronal cell bodies and neurites throughout the brain. 
Thus, transgenic $\alpha \mathrm{SYN}$ did not fail to be transported to synapses, but overexpression apparently caused pathological accumulations in neurons.

\section{MATERIALS AND METHODS}

Antibodies. Synthetic $\beta S Y N(87-101)$ peptide EEFPTDLKPEEVAQE coupled to keyhole limpet hemocyanin via an $\mathrm{N}$-terminal cysteine residue and keyhole limpet hemocyanin-coupled $\alpha \mathrm{SYN}(125-140)$ peptide YEMPSEEGYQDYEPEA and mouse $\alpha$ SYN(116-131) peptide MPVDPGSEAYEMPSEE were used to immunize rabbits (Eurogentec, Seraing, Belgium). The resulting antisera against $\beta$ SYN (6485), $\alpha$ SYN (6482), and mouse $\alpha$ SYN (7544) were used for Western probing at working dilution $1: 300$. Rat monoclonal antibody (Mc) $15 \mathrm{G} 7$ against human $\alpha \mathrm{SYN}(116-$ 131) peptide MPVDPDNEAYEMPSEE was produced in cooperation with Connex (Munich, Germany). The peptide was synthesized, directly coupled to keyhole limpet hemocyanin using 1-ethyl-3-(3-dimethylaminopropyl)carbodiimide, and used to immunize rats (Lou/c). Hybridoma supernatant was used diluted 1:5 on Western blots and undiluted for immunohistochemistry. Mouse Mc42 against rat $\alpha \mathrm{SYN}(15-123)\left(\mathrm{IgG}_{1}\right.$ used at working dilution 1:3000) was purchased from Transduction Laboratories (Lexington, KY), and rabbit polyclonal IgG 3400 against human $\alpha \mathrm{SYN}(117-131)$ peptide (working dilution 1:20,000) was from Affinit (Mamhead, UK). Mc SY38 hybridoma supernatant (working dilution 1:200) was kindly provided by W. W. Franke and R. E. Leube (Deutsches Krebsforschungszentrum, Heidelberg, Germany). Horseradish peroxidaseconjugated secondary antibodies (working dilution 1:5000) were purchased from Sigma (St. Louis, MO).

Antibody characterization. Purified recombinant human synucleins expressed in Escherichia coli were donated by P. H. Jensen (University of Ârhus, Århus, Denmark). $\alpha \mathrm{SYN}$ and $\beta S Y N$ purified from human brain (Baba et al., 1998) were kindly provided by T. Iwatsubo (University of Tokyo, Tokyo, Japan). Two micrograms of purified synuclein were subjected to SDS-PAGE (15\% polyacrylamide) and electroblotted onto polyvinylidene fluoride membrane $(0.45 \mu$ Immobilon-P; Millipore, Bedford, MA). Western blots were blocked with $5 \%$ skimmed milk and probed with the above antibodies as indicated. Chemiluminescence was generated with SuperSignal (Pierce, Rockford, IL) unless otherwise stated and visualized on X-Omat film (Eastman Kodak, Rochester, NY).

Heat-stable cytosolic fractions were prepared from human (temporal cortex, epilepsy lobotomy sample; University of Göttingen, Göttingen, Germany) and whole mouse brain as follows. Brain tissue was homogenized into $4-5 \mathrm{vol}$ of homogenization buffer [9\% sucrose, $5 \mathrm{~mm}$ dithiothreitol, $2 \mathrm{~mm}$ EDTA, $25 \mathrm{~mm}$ Tris, $\mathrm{pH}$ 7.0, plus Cømplete protease inhibitor cocktail (Boehringer Mannheim, Mannheim, Germany) by eight Potter strokes and processed as described previously (Jensen et al., 1998). Protein concentration in the $100,000 \times g$ supernatant was determined with the microplate protein assay (Bio-Rad, Hercules, CA). For each sample, $100 \mu \mathrm{g}$ of cytosolic brain protein was lyophilized after $10 \mathrm{~min}$ boiling and removal of the denatured protein pellet by $16,000 \times g$ centrifugation. The samples were processed for Western blotting as described above.

Subcellular fractionation and sucrose gradient floatation assay. C57BL/6 mice were ether-anesthetized and killed by decapitation, and whole brains were dissected. Human temporal cortex gray matter was available after lobotomy of epilepsy patients and kept refrigerated after surgery. Brain tissue was homogenized by eight Dounce strokes in 4-5 vol of homogenization buffer, and postnuclear fractions were prepared (Jensen et al., 1998) Subcellular fractionation and enrichment of synaptosomal compartments was performed as described previously (Huttner et al., 1983; George et al., 1995). Proteins from the membranous pellets and the dilute soluble synaptosomal contents (LP2) were precipitated with trichloroacetic acid. Precipitates were collected by $16,000 \times g$ centrif ugation, washed with $70 \%$ acetone, neutralized, and redissolved in Lämmli's buffer. Samples were resolved by $12.5 \%$ SDS-PAGE, and the corresponding Western blots were sequentially probed for SYNs and synaptophysin. When necessary, weak signals were detected with enhanced chemiluminescence ECLplus (Amersham Pharmacia Biotech, Little Chalfont, UK).

Sucrose gradient floatation assays (Jensen et al., 1998) were performed with material prepared from wild-type and transgenic mouse and human brain. Briefly, samples were brought to $55 \%$ sucrose and overlaid with linear sucrose gradients $(20-48$ or $30-48 \%)$. After equilibrium centrifugation, $1 \mathrm{ml}$ fractions were collected from the top (except fractions 1-4 of $20-48 \%$ sucrose gradients, $1.5 \mathrm{ml}$ ). The (soluble) protein-rich bottom fractions were discarded. The whole trichloroacetic acid precipitate from each gradient fraction was processed as described above, resolved by $12.5 \%$ SDS-PAGE or 4-20\% Tris-tricine-PAGE (Novex), and Western probed. Immunohistochemistry. Fresh mouse brains and autopsy-derived human cerebellum and temporal cortex were fixed in phosphate-buffered $4 \%$ paraformaldehyde and embedded in paraffin. Both an alkalinephosphatase anti-alkaline phosphatase technique and fluorescent labeling were used for immunocytochemical detection of $\alpha \mathrm{SYN}, \beta \mathrm{SYN}$, and synaptophysin. Sections (4- $\mu \mathrm{m}$-thick) were dewaxed in xylene and rehydrated using a descending ethanol series. To enhance immunoreactivity for $\alpha \mathrm{SYN}$, sections were boiled in $0.01 \mathrm{M}$ citrate buffer, $\mathrm{pH} 6.0$, in a microwave oven five times for 3 min. Incubation in PBS with $2 \%$ bovine serum albumin and $0.01 \%(\mathrm{v} / \mathrm{v})$ Triton X-100 was performed for 30 min to block nonspecific binding. Incubation with primary antibodies was performed for
$1.5 \mathrm{hr}$ at room temperature. Detection of antibody binding was done by the alkaline-phosphatase anti-alkaline phosphatase system according to the instructions of the manufacturer (Dako, High Wycombe, UK) using Neufuchsin as chromogen.

Double-immunolabeling of $\beta S Y N$ with either $\alpha \mathrm{SYN}$ or synaptophysin was performed with two different fluorophore-conjugated secondary antibodies. After incubation with the first primary antibody against $\beta S Y N$ for $1.5 \mathrm{hr}$, sections were incubated with tetramethyl rhodamine isothiocyanateconjugated goat anti-rabbit IgG for $30 \mathrm{~min}$. Then the second primary antibody (anti- $\alpha \mathrm{SYN}$ or anti-synaptophysin) was added for $1.5 \mathrm{hr}$ and detected using fluorescein-conjugated goat anti-rat and goat anti-mouse $\mathrm{IgG}$, respectively. Both antibodies were preabsorbed with rabbit IgG to minimize cross-reaction with the first primary antibody. Autofluorescence was blocked by staining the sections with the dye Sudan black B (Romijn et al., 1999). Sections were analyzed with the Leica (Nussloch, Germany) TCS-NT confocal laser scanning microscope.

Generation of transgenic mice. Wild-type human $\alpha$ SYN cDNA (396 bp) was amplified by PCR from $20 \mathrm{ng}$ of human brain cDNA (Clontech, Palo Alto, CA) and cloned into pMOSBlue (Amersham Pharmacia Biotech), and its identity was confirmed by sequencing. The cDNA was excised with NdeI and SmaI, blunted by Klenow reaction, and inserted into the blunted XhoI site of pTSC21k. The sequence encoding human [A30P] $\alpha$ SYN (Okochi et al., 2000) was amplified by PCR and subcloned into the XhoI site of pTSC21k. The Thy-1 cassette contains a modified EcoRI fragment of the mouse Thy-1.2 glycoprotein gene (Vidal et al., 1990; Moechars et al., 1996; Lüthi et al., 1997). A linear NotI DNA fragment comprising the transgene without plasmid vector sequences was isolated and injected into fertilized eggs at a concentration of $2 \mathrm{ng} / \mathrm{ml}$ according to standard techniques (Hogan et al. 1995). Founder mice were identified by PCR using primers specific for Thy-1 sequences located on both sides of the $\alpha \mathrm{SYN}$ insert leading to a $1 \mathrm{~kb}$ transgene-specific amplimer. Offspring was backcrossed into the C57BL/6 mouse strain.

RNA isolation and Northern blot analysis. RNA was isolated from total brain of mice at 2, 5, 10,16, and $20 \mathrm{~d}$ after birth. Organs were homogenized with beads in $0.9 \mathrm{ml}$ of RNAzol-0.1 ml of chloroform in a FP120 (Bio 101) following the recommendations of the manufacturer. Poly $\left(\mathrm{A}^{+}\right)$RNA selected from $50 \mu \mathrm{g}$ of total RNA (mRNA isolation kit; Roche Molecular Biochemicals) was separated on a $0.7 \%$ formaldehyde-agarose gel. RNA was blotted onto a Hybond ${ }^{+}$membrane (Amersham Pharmacia Biotech) and hybridized to single-stranded oligonucleotide probes specific for RNA of the human $\alpha$ SYN transgene (antisense nucleotides 260-320 of human $\alpha$ SYN open reading frame, 5'-CTCCTTCTTCATTCTTGCCCAACTGGTCCTTTTTGACAAAGCCAGTGGCTGCTGCAATGC-3'; and antisense nucleotides $1-30$ of human $\alpha \mathrm{SYN}$ open reading frame plus nucleotides -1 to -32 of upstream vector, 5'-CTTTGAAAGTCCTTTCATGAATACATCCATCTCGAGTGCCAAGAGTTCCGACTTGGATTCT-3') and mouse $\beta$-actin (5'-CCAGGGAGGAAGAGGATGCGGCAGTGGCCATCTCCTGCTCGAAGTCTAGAGCAACATAGC-3'). Probes had been labeled by the terminal deoxynucleotidyl transferase reaction with $\alpha-\left[{ }^{32} \mathrm{P}\right] \mathrm{dATP}(6000$ $\mathrm{Ci} / \mathrm{mmol}$; Amersham Pharmacia Biotech). Hybridization was done in Rapid Hybridization Buffer (Amersham Pharmacia Biotech) over night at $65^{\circ} \mathrm{C}$. Blots were washed in $2 \times \operatorname{SSPE}(+0.1 \%$ SDS $)$ at room temperature for 15 min, followed by a second wash for $15 \mathrm{~min}$ at $65^{\circ} \mathrm{C}$ and two further washes in $1 \times$ and $0.5 \times \operatorname{SSPE}(+0.1 \%$ SDS $)$ at $65^{\circ} \mathrm{C}$. Membranes were exposed to Biomax MR (Eastman Kodak) film.

\section{RESULTS}

\section{Selective detection of $\alpha S Y N$ and $\beta S Y N$}

Amino acids 87-101 located in close $\mathrm{C}$-terminal apposition to the NAC domain are absolutely conserved in all the mammalian $\beta S Y N$ sequences reported to date (Lavedan, 1998). To generate $\beta S Y N-$ specific antibodies that do not cross-react with other members of the synuclein family, rabbits were immunized with the $\beta S Y N$ peptide 87-101 to generate antiserum 6485. Antibody 6485 strongly reacted on Western blots with purified as well as recombinant $\beta S Y N$ (Fig. $1 A, B$ ). Human and mouse brain $\beta S Y N$ were both recognized (Fig. 1C). Preabsorption of antiserum 6485 with $1 \mathrm{mg} / \mathrm{ml}$ immunizing peptide completely abolished immunoreactivity on Western blots (results not shown). Antiserum 6485 showed no cross-reactivity with $\alpha \mathrm{SYN}$ and $\gamma \mathrm{SYN}$ (Fig. 1A,B). Moreover, anti- $\beta S Y N 6485$ immunoprecipitates were not detected with the $\alpha \mathrm{SYN}$-specific antibody Mc42 (Transduction Laboratories) and vice versa (data not shown). Therefore, antiserum 6485 can be used to specifically identify $\beta S Y N$ in human and mouse tissue.

Because we attempted to compare the cellular distribution of overexpressed human $[\mathrm{A} 30 \mathrm{P}] \alpha \mathrm{SYN}$ with endogenous $\alpha \mathrm{SYN}$ and $\beta S Y N$ in transgenic mice, we searched for antibodies that allow the exclusive identification of human $\alpha \mathrm{SYN}$. A double amino acid substitution is present close to the $\mathrm{C}$ termini of human and mouse 

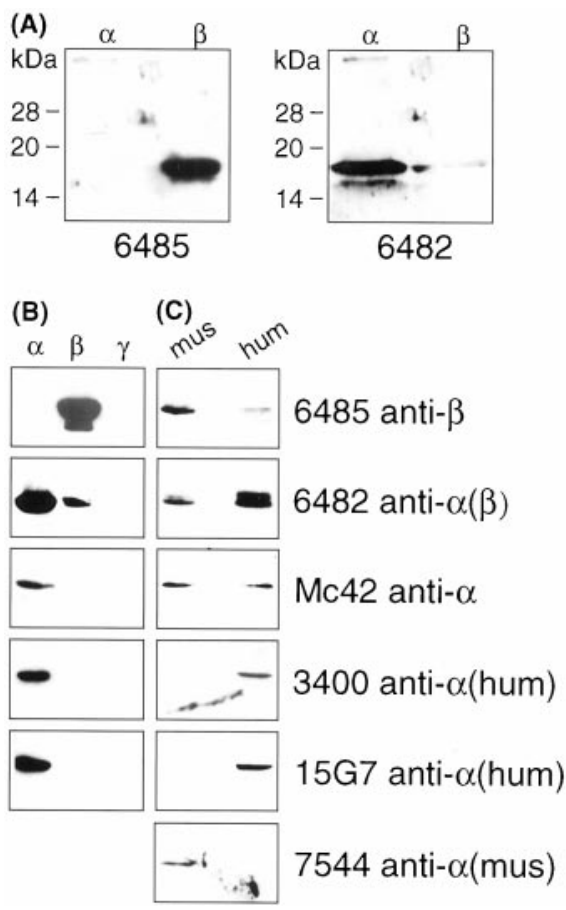

Figure 1. Selective detection of $\alpha \mathrm{SYN}$ and $\beta$ SYN. $A$, A Western blot prepared from $5 \mu \mathrm{g}$ of purified human brain $\alpha \mathrm{SYN}$ and $\beta S Y N$ was probed with antiserum 6485 (left) and then stripped and reprobed with antiserum 6482 (right). Antiserum 6485 specifically recognized $\beta S Y N$, whereas antiserum 6482 raised against the $\mathrm{C}$ terminus of $\alpha \mathrm{SYN}$ showed some crossreactivity toward $\beta S Y N$. The positions of prestained molecular weight markers are indicated to the left of each blot. $B$, Western blots were prepared from $5 \mu \mathrm{g}$ (top 2 panels) or $2 \mu \mathrm{g}$ (bottom 3 panels) of purified recombinant human $\alpha \mathrm{SYN}, \beta \mathrm{SYN}$, and $\gamma \mathrm{SYN}$. $C$, Heat-stable supernatant of mouse (mus) or human (hum) brain cytosol $(100 \mu \mathrm{g})$ was lyophilized and subjected to $15 \%$ SDS-PAGE. Blots were probed with the antibodies specified to the right.

$\alpha \mathrm{SYN}$. In the human sequence, amino acids 121-122 are Asp-Gln, whereas in mouse, the corresponding amino acids are Gly-Ser. The Mc15G7 raised against a peptide (human $\alpha \mathrm{SYN}$ residues 116-131) encompassing this region was indeed specific for human $\alpha \mathrm{SYN}$ (Fig. 1C). Likewise, the rabbit polyclonal antiserum 3400 (Affiniti) was specific for human $\alpha \mathrm{SYN}$ (Fig. 1C). Other human-specific $\alpha \mathrm{SYN}$ antibodies also recognize the same region (Jakes et al., 1994, 1999). Antibodies $15 \mathrm{G} 7$ and 3400 displayed no cross-reactivity toward $\beta$ SYN and $\gamma \mathrm{SYN}$ (Fig. $1 B$ ). Thus, antibodies $15 \mathrm{G} 7$ and 3400 were used to specifically detect transgenic human $[\mathrm{A} 30 \mathrm{P}] \alpha \mathrm{SYN}$ in genetically engineered mice (see below). On the other hand, we have raised antiserum 7544 against a peptide comprising amino acids $116-131$ of mouse $\alpha$ SYN that specifically recognized the rodent protein (Fig. $1 C$ ), with no cross-reactivity to $\beta S Y N$ and $\gamma \mathrm{SYN}$, as determined by immunoprecipitation-blotting experiments (data not shown). Finally, Mc42 recognized both mouse and human $\alpha \mathrm{SYN}$ (Fig. 1C).

Detection of $\alpha S Y N$ and $\beta S Y N$ in synaptosomal fractions

A sucrose gradient floatation assay has been used recently to describe synaptic vesicle association of $\alpha \mathrm{SYN}$ in rat brain (Jensen et al., 1998). After equilibrium centrifugation of a postnuclear fraction from mouse brain, $\beta S Y N$ was found in the highest density fraction 8 and also floated into the lower density fraction 6 (Fig. $2 A$ ). A very similar profile was observed for $\alpha \mathrm{SYN}$ (Fig. $2 A$ ). We also analyzed the distribution of the synaptic vesicle marker synaptophysin (Wiedenmann and Franke, 1985). Synaptophysin was exclusively identified in the floating fractions (Fig. $2 A$ ). As for the fresh mouse brain, $\alpha \mathrm{SYN}$ from rapidly processed human temporal cortex of an epilepsy patient after lobotomy was present in the highest density fraction 13, as well as in the floating lower density fractions (Fig. 2B). Again, synaptophysin was not found in the highest density fractions but was rather smeared throughout the lower density fractions (Fig. $2 B$ ).

When the floatation assay was performed with a $16,000 \times g$ supernatant of the mouse brain postnuclear fraction, both $\alpha \mathrm{SYN}$ and $\beta S Y N$ were depleted from the floating fractions and found exclusively in the highest density fractions (Fig. 2C). However, synaptophysin was detectable in the lower density fractions of $16,000 \times g$ supernatants, as observed in floatation assays from $1000 \times g$ supernatants. The synaptophysin-positive floating material in the $16,000 \times g$ supernatant might represent free synaptic vesicles. Synaptosomes are pelleted at $16,000 \times g$ (Huttner et al., 1983). Thus, the synuclein-positive material in the floating fractions of $1000 \times g$ supernatants might represent synaptosomes, because the signal is lost upon centrifugation with $16,000 \times g$.

To further prove this possibility, systematic subcellular fractionation (Huttner et al., 1983) (Fig. 2D) was performed with mouse brain (Fig. $2 E$ ). Abundant $\alpha \mathrm{SYN}$ immunoreactivity was detected in the postnuclear $(1000 \times g)$ supernatant $(\mathrm{S} 1)$ and in the $12,500 \times$ $g$ supernatant (S2). The S2 fraction was subsequently subjected to $100,000 \times g$ centrifugation. After this step, $\alpha \mathrm{SYN}$ was detected in the supernatant (S3, the cytosolic fraction). A significant fraction of $\alpha \mathrm{SYN}$ was also present in the $12,500 \times g$ pellet $(\mathrm{P} 2)$. This crude synaptosomal fraction was washed, lysed hypotonically, cleared by $25,000 \times g$ centrifugation, and subjected to $100,000 \times g$ centrif $u-$ gation. After centrifugation, $\alpha \mathrm{SYN}$ was found in the supernatant (LS2, the soluble content of synaptosomes). Reprobing the same membrane with antiserum 6485 revealed a similar subcellular distribution of $\beta S Y N$. The same subcellular distribution of $\alpha \mathrm{SYN}$ was found in the human epilepsy control brain (Fig. $2 F$ ). Synaptophysin was found in the $100,000 \times g$ pellets (P3 and LP2) and was particularly enriched in the synaptosomal preparations (LP2).

\section{Colocalization of $\alpha S Y N$ and $\beta S Y N$ in normal brain}

Our direct comparative biochemical experiments revealed that $\alpha \mathrm{SYN}$ and $\beta \mathrm{SYN}$ were reproducibly found in the same subcellular fractions. To confirm colocalization of $\alpha \mathrm{SYN}$ and $\beta \mathrm{SYN}$, we performed immunohistochemical experiments on human brain sections of temporal and cerebellar cortex. Immunostaining of temporal cortices revealed a strong synaptic neuropil staining throughout all cortical layers (data not shown). In the cerebellum, an intense staining was seen in the molecular layer, in discrete areas in the granule cell layer resembling cerebellar glomeruli, and around the somata of Purkinje cells (Fig. $3 A, B$ ). The cytoplasm of neuronal and glial cells, as well as the white matter, were immunonegative. The staining pattern was similar to that obtained with antibodies against synaptophysin (Fig. 3C). There were no different staining patterns in human and mouse brains.

To ascertain the colocalization of $\beta$ SYN with $\alpha \mathrm{SYN}$ as well as with synaptophysin, double-labeled immunofluorescent confocal laser scanning microscopy was performed. The $\beta S Y N$-positive structures showed a marked overlap with $\alpha \mathrm{SYN}$ and synaptophysin-positive synaptic structures enriched in the cerebellar glomeruli (Fig. 3D-I). Likewise, a virtually complete overlap was observed in the molecular layer (results not shown).

\section{Expression of [A30P] $\alpha S Y N$ in transgenic mice}

Patients heterozygous for the A30P mutation in the $\alpha \mathrm{SYN}$ gene developed an aggressive, early-onset form of PD (Krüger et al., 1998). To study the in vivo consequences of expression of $[\mathrm{A} 30 \mathrm{P}] \alpha \mathrm{SYN}$ in brain, transgenic mice were generated. Oozytes were microinjected with a construct that harbored the coding region of the human $\alpha \mathrm{SYN}$ cDNA bearing the A30P missense mutation (Fig. $4 A$ ). Expression of [A30P] $\alpha S Y N$ from this construct was driven by the brain neuron-specific Thy-1 promoter (Kollias et al., 1987). Transgenic offspring was backcrossed into the C57BL/6 mouse strain.

Northern and Western blot analysis revealed strong expression of transgenic human [A30P] $\alpha$ SYN mRNA and protein, respectively, in whole brain (Fig. 4). There was no difference in the expression and localization of synucleins between males and fe- 
(A) mouse

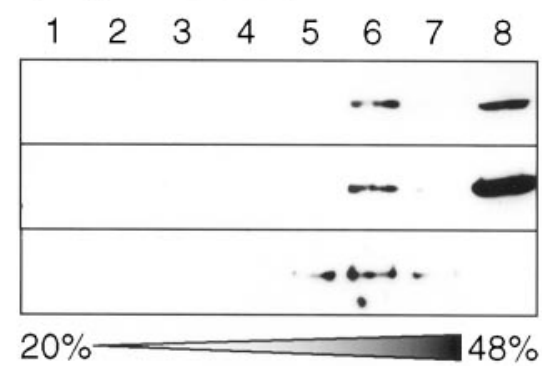

(C) synaptosome-depleted

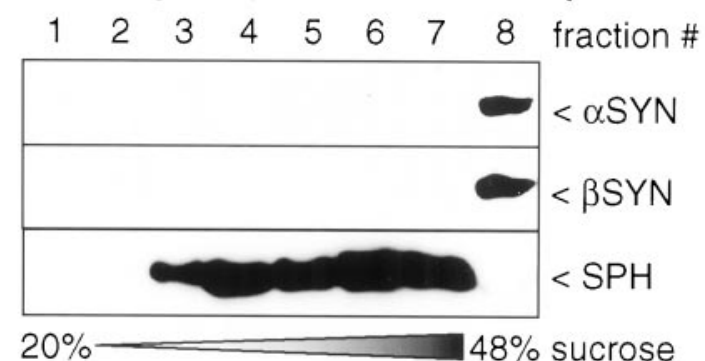

\section{(B) human}

Figure 2. Subcellular localization of synucleins in brain. Sucrose gradient $(20-$ $48 \%$ ) floatation assays were performed with $200 \mu \mathrm{l}$ of mouse postnuclear supernatant directly $(A)$ and after $16,000 \times g$ centrifugation $(C)$. Fractions were separated by SDS-PAGE $(12.5 \%)$, and Western blots were sequentially probed for $\alpha \mathrm{SYN}$ (top panel), $\beta \mathrm{SYN}$ (middle panel), and synaptophysin (bottom panel). Two additional experiments revealed the same results. $B$, Sucrose gradient $(30-48 \%)$ floatation assays were performed with postnuclear supernatant from rapidly processed temporal cortex gray matter of epilepsy patients after lobotomy. Fractions were subjected to Tris-tricine-PAGE (4$20 \%$ gradient), and Western blots were sequentially probed with Mc42 anti$\alpha \mathrm{SYN}$ (top panel) and anti-synaptophysin (bottom panel). ECL was used as chemiluminescence substrate. Tissue from an additional patient revealed the same result. $D$, Schematic representation of the subcellular fractionation steps. The postnuclear supernatant of one mouse brain $(E)$ (representative for 3 independent experiments) or biopsied temporal cortex gray matter of an epilepsy patient $(F)$ was subjected to subcellular fractionation. SDS-PAGE $(12.5 \%)$ was performed with $50 \mu \mathrm{g}$ (only $25 \mu \mathrm{g}$ were available of the synaptosomal pellet P2) (E) or $20 \mu \mathrm{g}$ (only $10 \mu \mathrm{g}$ were available of the synaptic vesicle pellet LP2) $(F)$ of each fraction. The corresponding Western blot was sequentially probed for $\alpha \mathrm{SYN}$ (top panels; $\mathrm{Mc} 42$ in $E$, $15 \mathrm{G} 7$ in $F$ ), $\beta \mathrm{SYN}$ (middle panels), and synaptophysin (bottom pan$e l s)$. ECL plus was used as chemiluminescence substrate in $F$.

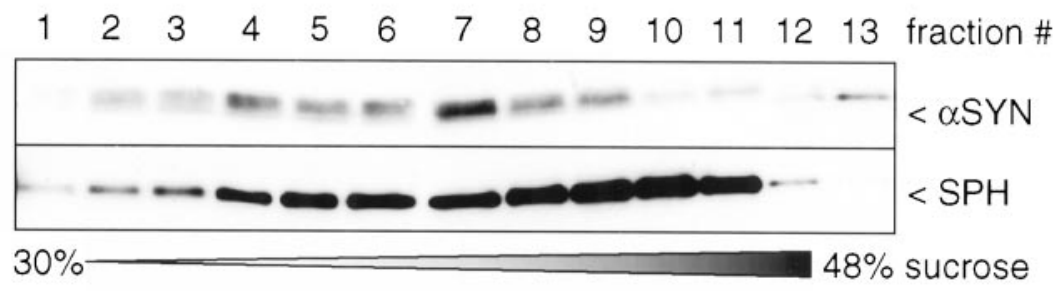

(D) fractionation

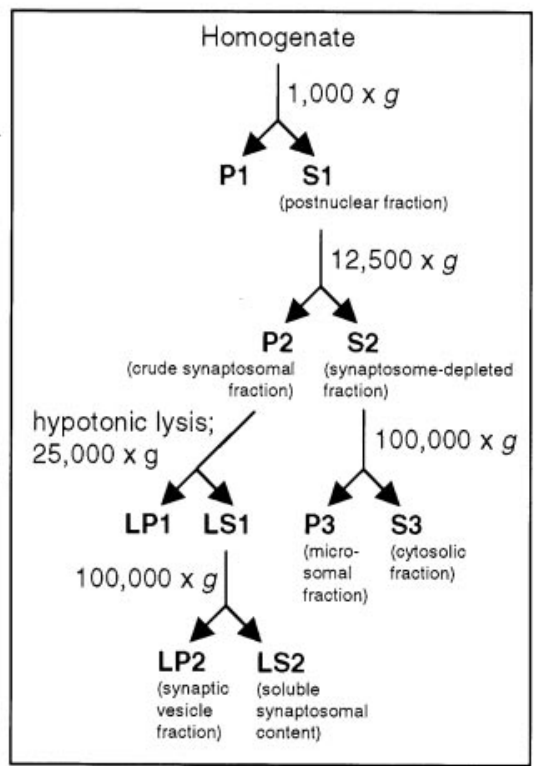

(E) mouse

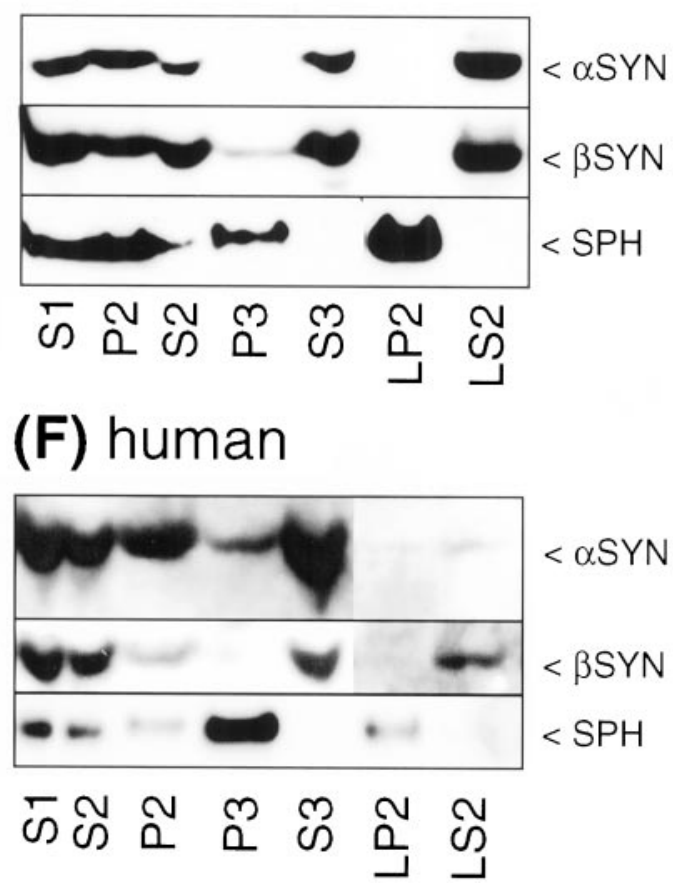

males (data not shown). Lines 18 and 31 consistently expressed higher levels of transgenic protein $(\sim 2-4$ times more) compared with lines 8,9, and 14. Judging from the Western blot probed with Mc42 that detected human and mouse $\alpha \mathrm{SYN}$ equally well (see Fig. $1 C$ ), transgenic overexpression in lines 18 and 31 was estimated to be approximately twofold relative to the endogenous $\alpha \mathrm{SYN}$ level. Small amounts of higher molecular weight species immunoreactive with anti- $\alpha$ SYN were occasionally observed (Fig. $4 E, F$ ). The motility of this double band was consistent with that of an $\alpha \mathrm{SYN}$ dimer. [A30P] $\alpha$ SYN expression was upregulated in the first postnatal month and remained high into old age (data not shown). This time course of expression approximately paralleled that of endogenous $\alpha \mathrm{SYN}$ in wild-type and transgenic mice (data not shown).

\section{Synaptosomal localization of [A30P] $\alpha$ SYN in transgenic mice}

Mutant [A30P] $\alpha \mathrm{SYN}$ was shown previously to associate less efficiently with cellular vesicles in in vitro assays (Jensen et al., 1998). Thus, a deficiency in axonal transport was suggested for [A30P] $\alpha$ SYN. To prove this possibility in vivo, whole brain homogenates of $[\mathrm{A} 30 \mathrm{P}] \alpha \mathrm{SYN}$-expressing mice were subjected to the sucrose gradient floatation assay. Immunoblotting with the humanspecific antibody 3400 revealed [A30P] $\alpha$ SYN in both the highest density fraction 9 and the synaptophysin-containing floating fractions (Fig. 5). In the same animal, a very similar distribution was shown by Mc42, which detected both endogenous mouse $\alpha \mathrm{SYN}$ 

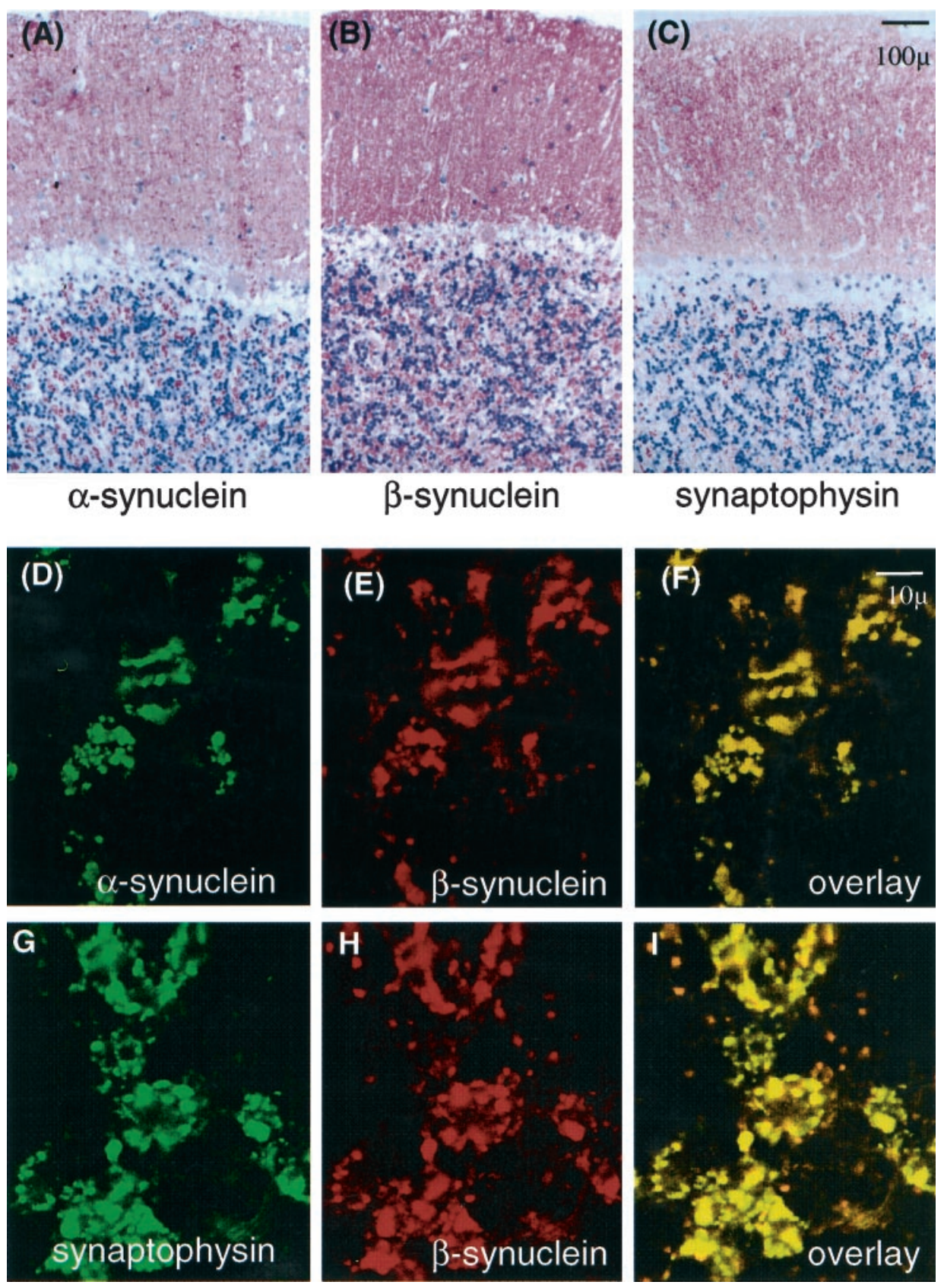

Figure 3. Colocalization of $\alpha \mathrm{SYN}$ and $\beta \mathrm{SYN}$ in human cerebellum. Antibodies 15G7 anti$\alpha$ SYN $(A), 6485$ anti- $\beta$ SYN $(B)$, and antisynaptophysin $(C)$ all stained a punctate pattern in the molecular layer. The immunoreactivity in the granule cell layer showed a patchy distribution corresponding to labeling of cerebellar glomeruli. Scale bar: $A-C, 100 \mu \mathrm{m}$. Double-labeled immunofluorescent confocal microscopy revealed a colocalization of $\alpha \mathrm{SYN}(D)$ and $\beta S Y N$ $(E)$ in the cerebellar glomeruli of the granule cell layer, which resulted in a yellow signal in the superimposed digital picture $(F)$. A similar colocalization is seen with synaptophysin $(G)$ and $\beta$ SYN $(H)$. I, Superimposed digital picture. Scale bar: $D-I, 10 \mu \mathrm{m}$. and transgenic human $[\mathrm{A} 30 \mathrm{P}] \alpha \mathrm{SYN}$. The high-expressing lines 18 and 31 and the low-expressing lines 8, 9, and 14 showed the same distribution of $[\mathrm{A} 30 \mathrm{P}] \alpha \mathrm{SYN}$ in the sucrose gradient (Fig. 5, and data not shown), thus excluding the possibility that high expression levels may overcome a partial loss of vesicle binding activity. These results suggest that $[\mathrm{A} 30 \mathrm{P}] \alpha \mathrm{SYN}$ is anterogradely transported to synapses in vivo (also see below).

\section{Abnormal accumulation of [A30P] $\alpha S Y N$ in neuronal cell bodies and neurites in transgenic mouse brain}

Immunohistochemistry using the human-specific antibody 15G7 was performed to visualize the subcellular localization of $\alpha \mathrm{SYN}$ in transgenic mouse brain sections (Fig. 6A-C). Transgenic mice expressing similar levels of human wild-type $\alpha \mathrm{SYN}$ were used as control. Normal neuropil and presynaptic staining of $[\mathrm{A} 30 \mathrm{P}] \alpha \mathrm{SYN}$ and wild-type $\alpha \mathrm{SYN}$ was evident throughout the brain, supporting our conclusion that both forms of $\alpha \mathrm{SYN}$ are anterogradely transported. In addition to the normal presynaptic localization, the human transgene-specific antibody $15 \mathrm{G} 7$ revealed a strong, diff use cytosolic immunostaining in neuronal cell bodies (Fig. 6B,C). In contrast, endogenous $\alpha \mathrm{SYN}$ was not observed in somal compartments with the mouse-specific antiserum 7544 (Fig. 6E,F). Moreover, abnormal $\alpha \mathrm{SYN}$-positive neurites were frequently observed (Fig. 7). Affected neurites contained diffuse $\alpha \mathrm{SYN}$ immunoreactivity and sometimes bulged into single or multiple varicosities over a stretch of several micrometers (Fig. $7 A, B, F, G$ ). Morphologically similar $\alpha \mathrm{SYN}$-positive swollen neurites are a characteristic feature of LB diseases (Fig. $7 H$ ). In mutant and wild-type transgenic mice, $\alpha \mathrm{SYN}$-positive neurites were occasionally seen to emanate from a neuronal cell body with accumulated $\alpha \mathrm{SYN}$ (Fig. 7A,B). Abnormal $\alpha \mathrm{SYN}$-positive profiles were observed in most brain areas, including the cerebellar Purkinje cells (Fig. 6B,C) and nucleus dentatus (Fig. $7 E-G$ ), substantia nigra and striatum, hippocampus, neocortex, and brainstem. Somal and neuritic accumulation of [A30P] $\alpha \mathrm{SYN}$ was similar in all five transgenic mouse lines and was observed in half-year-old and 1-year-old animals. In contrast, the staining patterns of antibodies against the endogenous mouse $\alpha \mathrm{SYN}$ (Fig. 7D), $\beta \mathrm{SYN}$ (Fig. 7C), and synaptophysin (results not shown) did not differ between nontransgenic and $\alpha \mathrm{SYN}$ transgenic 
(A) transgenic construct

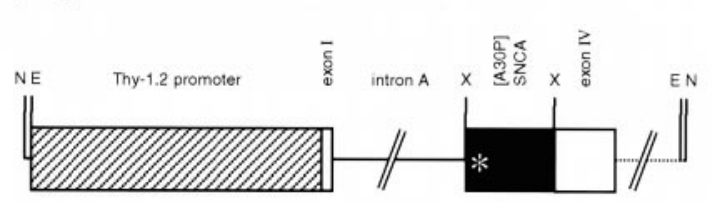

(C) 7544

(mouse-specific)

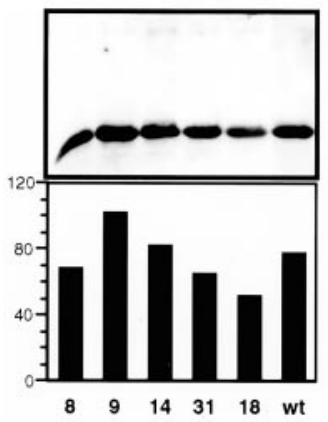

(D) Mc42

(human and mouse)

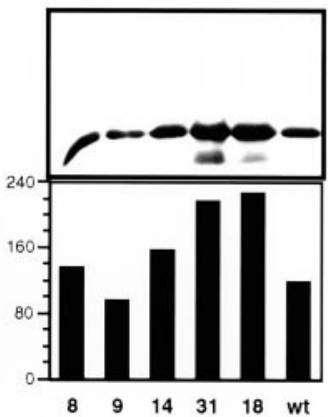

(B)

$\beta$-actin >
$\alpha S Y N>$
31

18

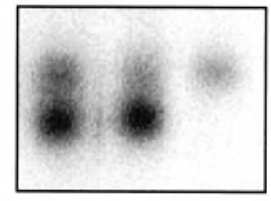

(E) 3400

(human-specific)

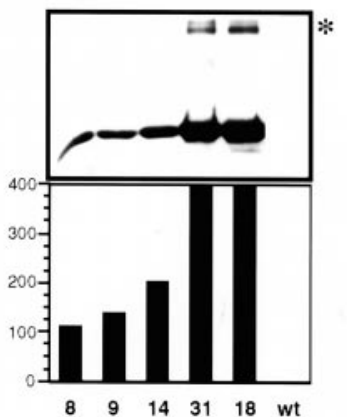

(F) 3400

(large gel)

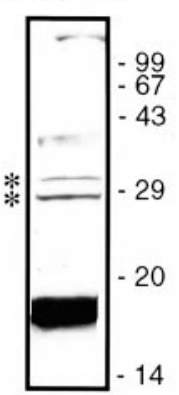

Figure 4. Expression of $[\mathrm{A} 30 \mathrm{P}] \alpha \mathrm{SYN}$ in transgenic mouse brain. A, Schematic drawing of the transgenic construct (not drawn to scale). Hatched box, mThy-1.2 promoter region. Open boxes, Thy-1 exonic sequences; (truncated) exon IV contains the polyadenylation signals. Solid line, Thy-1 intron A. Start and stop codons of the open reading frame for human $[\mathrm{A} 30 \mathrm{P}] \alpha \mathrm{SYN}$ ( filled box; *, A30P mutagenesis site) are directly flanked by XhoI restriction sites $(X)$. Dashed line, $3^{\prime}$-region of the Thy-1 gene. $N$, NotI restriction sites used to linearize construct and remove vector sequences before microinjection. $B$, A mixture of two probes specific for the human $\alpha$ SYN transgene and a probe for the mouse $\beta$-actin gene was hybridized to a Northern blot of poly $\left(\mathrm{A}^{+}\right)$ RNA from [A30P] $\alpha$ SYN mice, as indicated. The sizes of the transcripts were $\sim 1.8$ and $2.1 \mathrm{~kb}$, respectively. $C-E$, Lyophilized heat-stable supernatants of whole brain cytosol $(200 \mu \mathrm{g})$ from 6- to 10-week-old individuals of the indicated [A30P] $\alpha$ SYN mouse lines were subjected to $15 \%$ SDS-PAGE. Equal loading was demonstrated by Brilliant blue staining of the gels after transfer. Western blots were sequentially probed with the mouse-specific antiserum $7544(C), \operatorname{Mc} 42(D)$, and the human-specific antibody $3400(E)$. Bands were quantified by densitometric scanning (bottom panels). The data are representative for at least three animals per line screened for $[\mathrm{A} 30 \mathrm{P}] \alpha \mathrm{SYN}$ protein expression. $\alpha \mathrm{SYN}$-immunoreactive double bands (asterisks) comigrating with the $29 \mathrm{kDa}$ standard, a position consistent with the molecular mass of a dimer, were observed at variable intensity. These putative dimeric species could be well resolved in large gels (P10DS; Owl Separation Systems, Portsmouth, NH) $(F)$. Whole brain cytosol (600 $\mu \mathrm{g})$ from a 10-month-old line 18 mouse was directly subjected to $15 \%$ SDS-PAGE, without any concentration step. Western blot was probed with antibody 3400 .

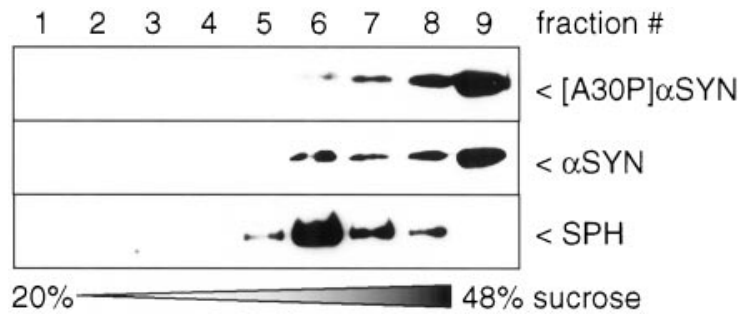

Figure 5. Synaptosomal localization of $[\mathrm{A} 30 \mathrm{P}] \alpha \mathrm{SYN}$ in transgenic mouse brain. Postnuclear supernatant from a 4-month-old male line 18 mouse was processed as described in Figure $2 A$. The Western blot was sequentially probed with antiserum 3400 (top panel), Mc42 (middle panel), and antisynaptophysin (bottom panel).

mice. Thus, the transport of synaptic vesicle proteins is not generally perturbed in the mice expressing human $\alpha \mathrm{SYN}$. Rather, the pathological accumulation in neuronal cell bodies and neurites is restricted to the transgenic human $\alpha \mathrm{SYN}$.

\section{DISCUSSION}

Using antibodies specific for selected members of the synuclein family, we demonstrated synaptic colocalization of $\alpha \mathrm{SYN}$ and $\beta S Y N$ in mouse and human brain. Biochemically, both $\alpha \mathrm{SYN}$ and $\beta S Y N$ were present in the same subcellular compartments, namely the cytosol and synaptosomes. Both synucleins were found throughout the brain, most prominently in the synapse-rich molecular layers of cerebellum (Fig. 6), neocortex (Fig. 7), hippocampus, and retina (data not shown). Double-labeled confocal microscopy revealed extensive colocalization of $\alpha \mathrm{SYN}$ and $\beta \mathrm{SYN}$. Most, if not all, synaptophysin-positive presynaptic terminals therefore contain both $\alpha \mathrm{SYN}$ and $\beta \mathrm{SYN}$, at least in human cerebellar cortex. Be- cause the same presynaptic staining was observed in (Thy-1)$\mathrm{h}[\mathrm{wt}] \alpha \mathrm{SYN}$ and (Thy-1)-h[A30P] $\alpha \mathrm{SYN}$ mice, the PD-associated A30P mutation did not abolish anterograde transport to the synaptic compartments in transgenic mouse brain. However, some perturbance of its axonal transport may be indicated by the accumulation of transgenic $\alpha \mathrm{SYN}$ in neuronal cell bodies and neurites.

$\alpha \mathrm{SYN}$ immunoreactivity in the lower density fractions of the recently described sucrose gradient floatation assay has been interpreted as interaction of $\alpha \mathrm{SYN}$ with synaptic vesicles (Jensen et al., 1998). However, centrifugation at relatively low force $(16,000 \times g)$ depleted synucleins from the floating fractions (Fig. 2C). Centrifugation at this force is sufficient to pellet synaptosomes (Huttner et al., 1983). $\alpha \mathrm{SYN}$ and $\beta S Y N$ were indeed present in the synaptosomal pellet P2 upon subcellular fractionation of mouse brain. Lysis of the synaptosomal pellet was followed by recovery of synucleins from the $100,000 \times g$ supernatant LS2. In contrast, synaptophysin was quantitatively recovered from the $100,000 \times g$ pellet LP2, which contains synaptic vesicles (Huttner et al., 1983). Moreover, some synaptophysin was detected in the $100,000 \times g$ pellet P3 (Fig. 2D), as well as in the synuclein-depleted floating fractions from a $16,000 \times g$ supernatant (Fig. $2 C$ ). Thus, if synucleins are bound to synaptic vesicles, as visualized by the punctate immunostaining of primary neuron cultures (Shibayama-Imazu et al., 1993; Withers et al., 1997) and demonstrated by the in vitro interaction of $\alpha \mathrm{SYN}$ with synthetic membranes and a crude vesicle preparation (Davidson et al., 1998; Jensen et al., 1998), the interaction appears to be reversible. Dilution in the process of the floatation assay and the hypotonic lysis of synaptosomes may dissociate the putative synuclein-synaptic vesicle complex. Both methods involved at least 10 -fold dilution in the sucrose gradient and water, respectively. In contrast, insertion of the membranespanning protein synaptophysin (Wiedenmann and Franke, 1985) 

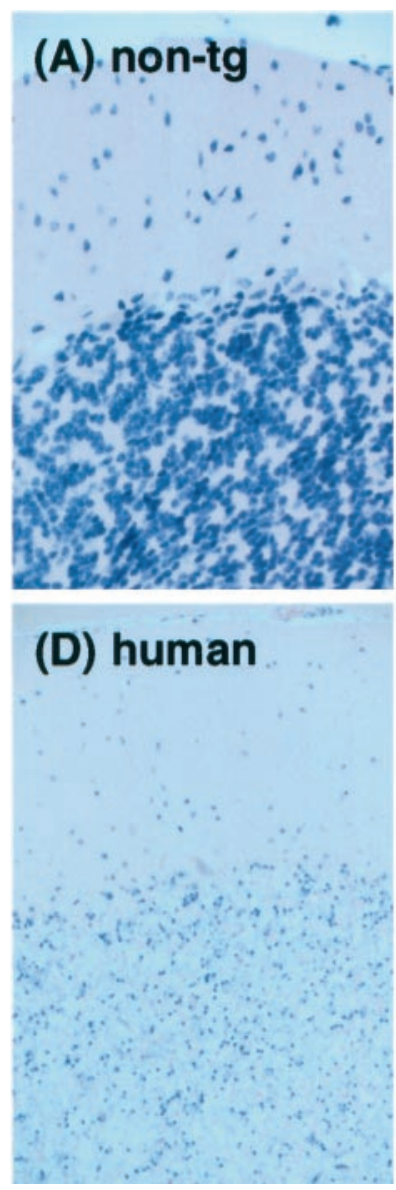
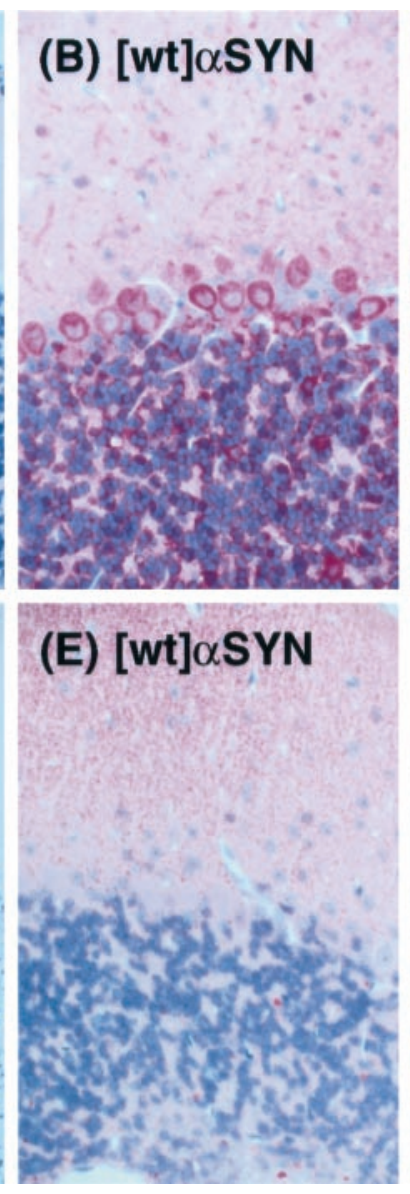
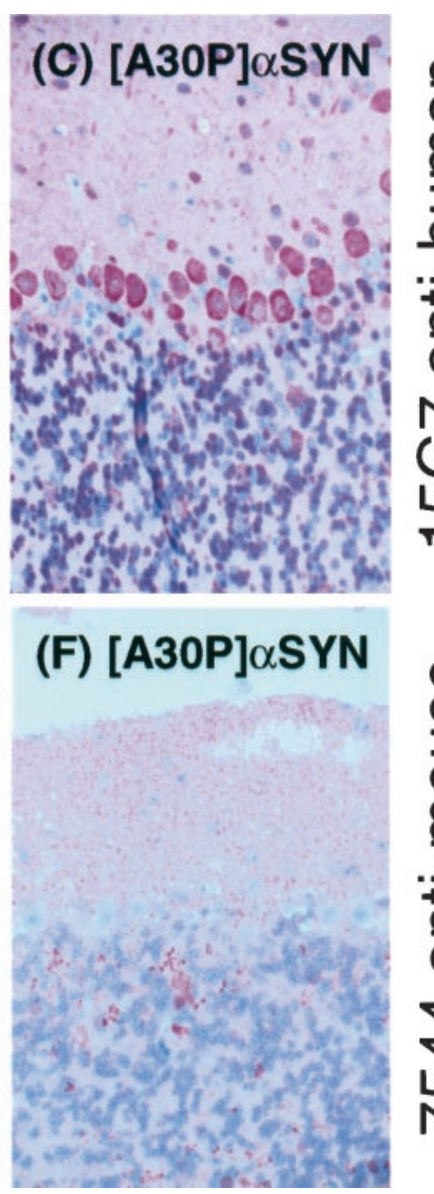
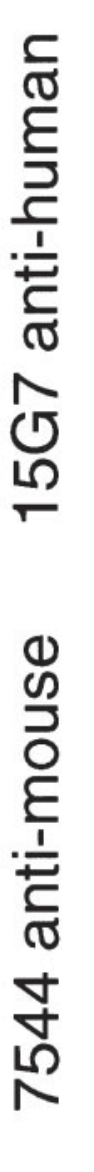

Figure 6. Distribution of transgenic and endogenous $\alpha \mathrm{SYN}$ in cerebellar sections. The human-specific antibody $15 \mathrm{G} 7 \mathrm{did}$ not react with nontransgenic mouse cerebellar sections $(A)$ but showed strong labeling of the molecular layer in [wt] $\alpha$ SYN mice $(B)$ and line 31 $[\mathrm{A} 30 \mathrm{P}] \alpha \mathrm{SYN}(C)$ mice. In addition, diffuse cytosolic immunoreactivity was observed in Purkinje cells of both transgenic mice. The mouse-specific antiserum 7544 did not show a specific signal with human cerebellar sections $(D)$. A normal synaptic staining pattern of endogenous $\alpha \mathrm{SYN}$ with labeling of the molecular layer and cerebellar glomeruli was observed in [wt] $\alpha$ SYN mice $(E)$ and line 31 $[\mathrm{A} 30 \mathrm{P}] \alpha \mathrm{SYN}$ mice $(F)$. Note that no cytosolic staining was observed with the antiserum 7544 in the transgenic mice. into synaptic vesicles is expected to be resistant to these procedures. The $\alpha \mathrm{SYN}$ and $\beta \mathrm{SYN}$ present in floating fractions from the brain postnuclear fraction may arise from synaptic vesicles trapped in synaptosomes. Consistent with this interpretation is the identification of the synaptosomal-associated protein SNAP-25, a presynaptic membrane marker (Söllner et al., 1993), in the $\alpha \mathrm{SYN}$ positive floating fractions (Jensen et al., 1998). Synaptosomal synucleins were also recovered in LS2 in previous studies of rat brain (Maroteaux and Scheller, 1991; Shibayama-Imazu et al., 1993; George et al., 1995). Irizarry et al. (1996), however, reported an equal distribution of $\alpha \mathrm{SYN}$ in the synaptosomal supernatants (LS2) and pellets (LP2) prepared from postmortem human temporal cortex. Methodological (fresh vs postmortem brain) differences may account for this finding.

Immunoreactivity in the cerebellar molecular layer, circumventing Purkinje cells, and particularly intense staining of cerebellar glomeruli in the granule cell layer of rat and canary has been detected previously with antibodies against $\alpha \mathrm{SYN}$ and $\beta \mathrm{SYN}$ (Shibayama-Imazu et al., 1993; Jakes et al., 1994; George et al., 1995; Iwai et al., 1995). The distribution of these proteins was similar in mouse brain. Double-stained confocal microscopy demonstrated virtually complete overlap of $\alpha \mathrm{SYN}, \beta S \mathrm{YN}$, and synaptophysin. We were not able to identify $\alpha \mathrm{SYN}$-specific or $\beta S Y N$ specific synapses. The extensive colocalization of $\alpha \mathrm{SYN}$ and $\beta \mathrm{SYN}$ suggests that they are spatially close and thus in a position to be functionally redundant.

It has been proposed that $[\mathrm{A} 30 \mathrm{P}] \alpha \mathrm{SYN}$ is less efficiently transported along the axon (Jensen et al., 1998, 1999). However, we observed a normal synaptosomal localization and presynaptic distribution of wild-type and $[\mathrm{A} 30 \mathrm{P}] \alpha \mathrm{SYN}$ in transgenic mouse brain. Thus, anterograde transport of $\alpha \mathrm{SYN}$ in vivo was not severely abolished by the A30P mutation. Likewise, no difference in subcellular targeting was found in primary neurons transfected with wild-type and mutant $\alpha$ SYN (McLean et al., 2000).
Nevertheless, a perturbance of axonal transport was indicated by the accumulation of $\alpha \mathrm{SYN}$ in neuronal cell bodies and neurites, which was observed in transgenic mice expressing wild-type and [A30P] $\alpha \mathrm{SYN}$. Endogenous mouse $\alpha \mathrm{SYN}$ was not retained in the pathological cell bodies and neurites. Moreover, neither $\beta S Y N$ nor synaptophysin were found within these [A30P] $\alpha$ SYN-positive profiles. Thus, somal and neuritic accumulation is a specific feature of transgenic human $\alpha \mathrm{SYN}$ and not simply attributable to an overload of the machinery transporting synaptic vesicle proteins.

Somal accumulation of $\alpha \mathrm{SYN}$ was found in mice subjected to a chronic 1-methyl-4-phenyl-1,2,3,6-tetrahydropyridine (MPTP) regimen causing apoptotic death of dopaminergic neurons, whereas acute MPTP toxicity had no effect on $\alpha \mathrm{SYN}$ expression (Vila et al., 2000). Similar findings were made in rat and baboon models of dopaminergic neuron apoptosis (Kholodilov et al., 1999; Kowall et al., 2000). We have not detected any apoptotic profiles in the $[\mathrm{A} 30 \mathrm{P}] \alpha \mathrm{SYN}$ mice. Thus, the observed somal (and neuritic) accumulation is not a consequence of apoptosis.

While this work was under consideration, human $\alpha \mathrm{SYN}$ (both wild-type and PD mutant) expressed in transgenic Drosophila melanogaster was demonstrated to form the $7-10 \mathrm{~nm}$ fibrils that are characteristic for human LBs (Feany and Bender, 2000). The only difference found in this study was a more rapid decline in climbing behavior in the mutant [A30P] $\alpha \mathrm{SYN}$ transgenic animals compared with [wt] $\alpha$ SYN flies. Recently, a transgenic mouse line greatly overexpressing human wild-type $\alpha \mathrm{SYN}$ under the control of the human PDGF- $\beta$ promoter was presented (Masliah et al., 2000). These animals showed amorphous precipitates of $\alpha \mathrm{SYN}$ in the cytoplasm but also in the rough endoplasmic reticulum and the nucleus. Decreases in dopaminergic markers and locomotor performance were reported. Our (Thy-1)-h[A30P] $\alpha \mathrm{SYN}$ mice showed no movement disability, up to 1 year of age. Apparently the neurons were able to cope with the load of transgenic $[\mathrm{A} 30 \mathrm{P}] \alpha \mathrm{SYN}$, despite its tendency to form fibrils in vitro (Giasson 

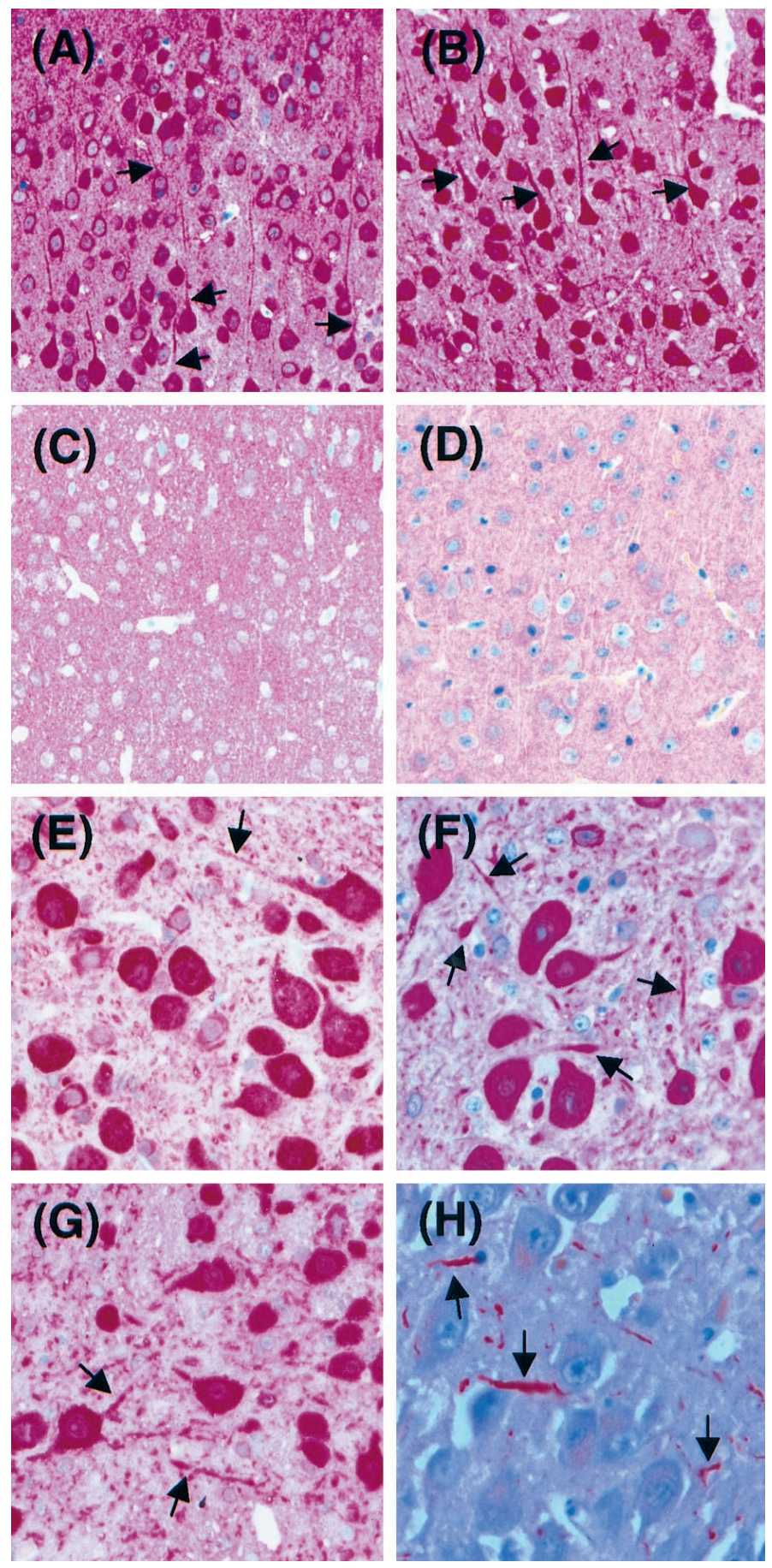

Figure 7. Accumulation of human $\alpha \mathrm{SYN}$ in neuronal cell bodies and neurites of transgenic mouse brain. Abnormal accumulation of human $[\mathrm{A} 30 \mathrm{P}] \alpha \mathrm{SYN}$ was detected in cell bodies and bulbous neurites in most brain regions, including frontal cortex [ $A$ (line 31$)$ and $B$ (line 18), 15G7]. Some $[\mathrm{A} 30 \mathrm{P}] \alpha \mathrm{SYN}$-filled neurites (arrows) emanated from neuronal cell bodies with accumulated [A30P] $\alpha$ SYN $(A, B)$. In contrast, expression of $\beta S Y N(C$ antiserum 6485) and endogenous $\alpha \mathrm{SYN}(D$, antiserum 7544) was restricted to the neuropil and was not found in neuronal cell bodies and neurites accumulating [A30P] $\alpha$ SYN. Pathological bulbous $\alpha$ SYN-positive neurites (arrows) could also be observed in the dentate nucleus of [wt] $(E)$ and [A30P] [line $31(F)$ and line $18(G)$; arrows] mice (15G7 staining). H, Lewy neurites (arrows) stained with 15G7 in the hippocampal CA2/3 region of a patient with LB dementia.

et al., 1999). The pathological accumulations of overexpressed $\mathrm{h}[\mathrm{A} 30 \mathrm{P}] \alpha \mathrm{SYN}$ might represent early stages of pathological abnormalities, which could finally lead to PD-like phenotype. It remains to be shown whether additional cofactors are required to induce fibril formation and generation of LB-like deposits in vertebrate brain.

\section{REFERENCES}

Abeliovich A, Schmitz Y, Fariñas I, Choi-Lundberg D, Ho W-H, Castillo PE, Shinsky N, Garcia Verdugo JM, Armanini M, Ryan A, Hynes M, Phillips H, Sulzer D, Rosenthal A (2000) Mice lacking $\alpha$-synuclein display functional deficits in the nigrostriatal dopamine system. Neuron 25:239-252.

Arawaka S, Saito Y, Murayama S, Mori H (1998) Lewy body in neurodegeneration with brain iron accumulation type 1 is immunoreactive for $\alpha$-synuclein. Neurology 51:887-889.

Arima K, Uéda K, Sunohara N, Hirai S, Izumiyama Y, Tonozuka-Uehara H, Kawai M (1998) Immunoelectron-microscopic demonstration of $\mathrm{NACP} / \alpha$-synuclein-epitopes on the filamentous component of Lewy bodies in Parkinson's disease and in dementia with Lewy bodies. Brain Res 808:93-100.

Baba M, Nakajo S, Tu P-H, Tomita T, Nakaya K, Lee VM-Y, Trojanowski JQ, Iwatsubo T (1998) Aggregation of $\alpha$-synuclein in Lewy bodies of sporadic Parkinson's disease and dementia with Lewy bodies. Am J Pathol 152:879-884.

Conway KA, Harper JD, Lansbury PT (1998) Accelerated in vitro fibril formation by a mutant $\alpha$-synuclein linked to early-onset Parkinson disease. Nat Med 4:1318-1320.

Culvenor JG, McLean CA, Cutt S, Campbell BCV, Maher F, Jäkälä P, Hartmann T, Beyreuther K, Masters CL, Li Q-X (1999) Non-A $\beta$ component of Alzheimer's disease amyloid (NAC) revisited: NAC and $\alpha$-synuclein are not associated with $\mathrm{A} \beta$ amyloid. Am J Pathol 155:1173-1181.

Davidson WS, Jonas A, Clayton DF, George JM (1998) Stabilization of $\alpha$-synuclein secondary structure upon binding to synthetic membranes. J Biol Chem 273:9443-9449.

Engelender S, Kaminsky Z, Guo X, Sharp AH, Amaravi RK, Kleiderlein JJ, Margolis RL, Troncoso JC, Lanahan AA, Worley PF, Dawson VL, Dawson TM, Ross CA (1999) Synphilin-1 associates with $\alpha$-synuclein and promotes the formation of cytosolic inclusions. Nat Genet $22: 110-114$

Feany MB, Bender WW (2000) A Drosophila model of Parkinson's disease. Nature 404:394-398.

George JM, Jin H, Woods WS, Clayton DF (1995) Characterization of a novel protein regulated during the critical period for song learning in the zebra finch. Neuron 15:361-372.

Giasson BI, Uryu K, Trojanowski JQ, Lee VM-Y (1999) Mutant and wild type human $\alpha$-synucleins assemble into elongated filaments with distinct morphologies in vitro. J Biol Chem 274:7619-7622.

Hardy J, Gwinn-Hardy K (1998) Genetic classification of primary neurodegenerative disease. Science 282:1075-1079.

Hogan B, Constantini F, Lacy E (1995) Manipulating the mouse embryo: a laboratory manual, Ed 2, pp 89-204. Plainview, NY: Cold Spring Harbor Laboratory.

Huttner WB, Schiebler W, Greengard P, De Camilli P (1983) Synapsin I (protein I), a nerve terminal-specific phosphoprotein. III. Its association with synaptic vesicles studied in a highly purified synaptic vesicle preparation. J Cell Biol 96:1374-1388.

Irizarry MC, Kim T-W, McNamara M, Tanzi RE, George JM, Clayton DF, Hyman BT (1996) Characterization of the precursor protein of the non-A $\beta$ component of senile plaques (NACP) in the human central nervous system. J Neuropathol Exp Neurol 55:889-895.

Iwai A, Masliah E, Yoshimoto M, Ge N, Flanagan L, Rohan de Silva HA, Kittel A, Saitoh T (1995) The precursor protein of non-A $\beta$ component of Alzheimer's disease amyloid is a presynaptic protein of the central nervous system. Neuron 14:467-475.

Jakes R, Spillantini MG, Goedert M (1994) Identification of two distinct synucleins from human brain. FEBS Lett 345:27-32.

Jakes R, Crowther RA, Lee VM-Y, Trojanowski JQ, Iwatsubo T, Goedert M (1999) Epitope mapping of LB509, a monoclonal antibody directed against human $\alpha$-synuclein. Neurosci Lett 269:13-16.

Jenco JM, Rawlingson A, Daniels B, Morris AJ (1998) Regulation of phospholipase D2: selective inhibition of mammalian phospholipase D isoenzymes by $\alpha$ - and $\beta$-synucleins. Biochemistry 37:4901-4909.

Jensen PH, Nielsen MS, Jakes R, Dotti CG, Goedert M (1998) Binding of $\alpha$-synuclein to brain vesicles is abolished by familial Parkinson's disease mutation. J Biol Chem 273:26292-26294.

Jensen PH, Hager H, Nielsen MS, Højrup P, Gliemann J, Jakes R (1999) $\alpha$-Synuclein binds to tau and stimulates the protein kinase A-catalyzed tau phosphorylation of serine residues 262 and 356. J Biol Chem 274:25481-25489.

Kholodilov NG, Neystat M, Oo TF, Lo SE, Larsen KE, Sulzer D, Burke RE (1999) Increased expression of rat synuclein in the substantia nigra pars compacta identified by mRNA differential display in a model of developmental target injury. J Neurochem 73:2586-2599.

Kollias G, Spanopoulou E, Grosveld F, Ritter M, Beech J, Morris R (1987) Differential regulation of a Thy-1 gene in transgenic mice. Proc Natl Acad Sci USA 84:1492-1496.

Kowall NW, Hantraye P, Brouillet E, Beal MF, McKee AC, Ferrante RJ (2000) MPTP induces alpha-synuclein aggregation in the substantia nigra of baboons. NeuroReport 11:211-213. 
Krüger R, Kuhn W, Müller T, Woitalla D, Graeber M, Kösel S, Przuntek H, Epplen JT, Schöls L, Riess O (1998) Ala30Pro mutation in the gene encoding $\alpha$-synuclein in Parkinson's disease. Nat Genet 18:106-108.

Lansbury Jr PT (1999) Evolution of amyloid: what normal protein folding may tell us about fibrillogenesis and disease. Proc Natl Acad Sci USA 96:3342-3344.

Lavedan C (1998) The synuclein family. Genome Res 8:871-880.

Lippa CF, Fujiwara H, Mann DMA, Giasson B, Baba M, Schmidt ML, Nee LE, O'Connell B, Pollen DA, St. George-Hyslop P, Ghetti B, Nochlin D, Bird TD, Cairns NJ, Lee VM-Y, Iwatsubo T, Trojanowski JQ (1998) Lewy bodies contain altered $\alpha$-synuclein in brains of many familia Alzheimer's disease patients with mutations in presenilin and amyloid precursor protein genes. Am J Pathol 153:1365-1370.

Lippa CF, Schmidt ML, Lee V M-Y, Trojanowski JQ (1999) Antibodies to $\alpha$-synuclein detect Lewy bodies in many Down's syndrome brains with Alzheimer's disease. Ann Neurol 45:353-357.

Lüthi A, van der Putten H, Botteri FM, Mansuy IM, Meins M, Frey U, Sansig G, Portet C, Schmutz M, Schröder M, Nitsch C, Laurent J-P, Monard D (1997) Endogenous serine protease inhibitor modulates epileptic activity and hippocampal long-term potentiation. J Neurosci 17:4688-4699.

Maroteaux L, Scheller RH (1991) The rat brain synucleins; family of proteins transiently associated with neuronal membrane. Mol Brain Res 11:335-343.

Masliah E, Rockenstein E, Veinbergs I, Mallory M, Hashimoto M, Takeda A, Sagara Y, Sisk A, Mucke L (2000) Dopaminergic loss and inclusion body formation in $\alpha$-synuclein mice: implications for neurodegenerative disorders. Science 287:1265-1269.

McLean PJ, Kawamata H, Ribich S, Hyman BT (2000) Membrane association and protein conformation of $\alpha$-synuclein in intact neurons. J Bio Chem 275:8812-8816.

Moechars D, Lorent K, De Strooper B, Dewachter I, Van Leuven F (1996) Expression in brain of amyloid precursor protein mutated in the $\alpha$-secretase site causes disturbed behavior, neuronal degeneration and premature death in transgenic mice. EMBO J 15:1265-1274.

Nakajo S, Tsukada K, Omata K, Nakamura Y, Nakaya K (1993) A new brain-specific $14-\mathrm{kDa}$ protein is a phosphoprotein. Its complete amino acid sequence and evidence for phosphorylation. Eur J Biochem 217:1057-1063.

Narhi L, Wood SJ, Steavenson S, Jiang Y, Wu GM, Anafi D, Kaufman SA, Martin F, Sitney K, Denis P, Louis J-C, Wypych J, Biere AL, Citron M (1999) Both familial Parkinson's disease mutations accelerate $\alpha$-synuclein aggregation. J Biol Chem 274:9843-9846.

Okochi M, Walter J, Koyama A, Nakajo S, Baba M, Iwatsubo T, Meijer L, Kahle PJ, Haass C (2000) Constitutive phosphorylation of the Parkinson's disease associated $\alpha$-synuclein. J Biol Chem 275:390-397.

Ostrerova N, Petrucelli L, Farrer M, Mehta N, Choi P, Hardy J, Wolozin B (1999) $\alpha$-Synuclein shares physical and functional homology with 14-3-3 proteins. J Neurosci 19:5782-5791.

Polymeropoulos MH, Lavedan C, Leroy E, Ide SE, Dehejia A, Dutra A, Pike B, Root H, Rubenstein J, Boyer R, Stenroos ES, Chandrasekharappa S, Athanassiadou A, Papapetropoulos T, Johnson WG, Lazzarini AM, Duvoisin RC, Di Iorio G, Golbe LI, Nussbaum RL (1997) Mutation in the $\alpha$-synuclein gene identified in families with Parkinson's disease. Science 276:2045-2047.

Romijn HJ, van Uum JF, Breedijk I, Emmering J, Radu I, Pool CW (1999) Double immunolabeling of neuropeptides in the human hypothalamus as analyzed by confocal laser scanning fluorescence microscopy. J Histochem Cytochem 47:229-236.

Selkoe DJ (1999) Translating cell biology into therapeutic advances in Alzheimer's disease. Nature 399:A23-A31.

Shibayama-Imazu T, Okahashi I, Omata K, Nakajo S, Ochiai H, Nakai Y, Hama T, Nakamura Y, Nakaya K (1993) Cell and tissue distribution and developmental change of neuron specific $14 \mathrm{kDa}$ protein (phosphoneuroprotein 14). Brain Res 622:17-25.

Söllner T, Bennett MK, Whiteheart SW, Scheller RH, Rothman JE (1993) A protein assembly-disassembly pathway in vitro that may correspond to sequential steps of synaptic vesicle docking, activation, and fusion. Cell $75: 409-418$

Spillantini MG, Schmidt ML, Lee VM-Y, Trojanowski JQ, Jakes R, Goedert M (1997) $\alpha$-Synuclein in Lewy bodies. Nature 388:839-840.

Spillantini MG, Crowther RA, Jakes R, Cairns NJ, Lantos PL, Goedert M (1998) Filamentous $\alpha$-synuclein inclusions link multiple system atrophy with Parkinson's disease and dementia with Lewy bodies. Neurosci Lett 251:205-208.

Surguchov A, Surgucheva I, Solessio E, Baehr W (1999) Synoretin-a new protein belonging to the synuclein family. Mol Cell Neurosci 13:95-103.

Takeda A, Hashimoto M, Mallory M, Sundsumo M, Hansen L, Sisk A, Masliah E (1998a) Abnormal distribution of the non-A $\beta$ component of Alzheimer's disease amyloid precursor $/ \alpha$-synuclein in Lewy body disease as revealed by proteinase $\mathrm{K}$ and formic acid pretreatment. Lab Invest 78:1169-1177.

Takeda A, Mallory M, Sundsmo M, Honer W, Hansen L, Masliah E (1998b) Abnormal accumulation of $\mathrm{NACP} / \alpha$-synuclein in neurodegenerative disorders. Am J Pathol 152:367-372.

Tu P, Galvin JE, Baba M, Giasson B, Tomita T, Leight S, Nakajo S, Iwatsubo T, Trojanowski JQ, Lee VM-Y (1998) Glial cytoplasmic inclusions in white matter oligodendrocytes of multiple system atrophy brains contain insoluble $\alpha$-synuclein. Ann Neurol 44:415-422.

Uéda K, Fukushima H, Masliah E, Xia Y, Iwai A, Yoshimoto M, Otero DA, Kondo J, Ihara Y, Saitoh T (1993) Molecular cloning of cDNA encoding an unrecognized component of amyloid in Alzheimer disease. Proc Natl Acad Sci USA 90:11282-11286.

Vidal M, Morris R, Grosveld F, Spanopoulou E (1990) Tissue-specific control elements of the Thy-1 gene. EMBO J 9:833-840.

Vila M, Vukosavic S, Jackson-Lewis V, Neystat M, Jakowec M, Przedborski S (2000) $\alpha$-Synuclein up-regulation in substantia nigra dopaminergic neurons following administration of the parkinsonian toxin MPTP. J Neurochem 74:721-729.

Wakabayashi K, Hayashi S, Kakita A, Yamada M, Toyoshima Y, Yoshimoto M, Takahashi H (1998) Accumulation of $\alpha$-synuclein/NACP is a cytopathological feature common to Lewy body disease and multiple system atrophy. Acta Neuropathol 96:445-452.

Wakabayashi K, Yoshimoto M, Fukushima T, Koide R, Horikawa Y, Morita T, Takahashi H (1999) Widespread occurrence of $\alpha$-synuclein/ NACP-immunoreactive neuronal inclusions in juvenile and adult-onset Hallervorden-Spatz disease with Lewy bodies. Neuropathol Appl Neurobiol 25:363-368.

Wiedenmann B, Franke WW (1985) Identification and localization of synaptophysin, an integral membrane glycoprotein of $\mathrm{M}_{\mathrm{r}} 38,000$ characteristic of presynaptic vesicles. Cell 41:1017-1028.

Withers GS, George JM, Banker GA, Clayton DF (1997) Delayed localization of synelfin (synuclein, NACP) to presynaptic terminals in cultured rat hippocampal neurons. Dev Brain Res 99:87-94. 